\title{
FIGURACIONES MODÉLICAS Y ANTIMODÉLICAS DEL MILITAR EN LA OBRA DE FERNÁNDEZ DE LIZARDI
}

\author{
Mariela Insúa \\ GRISO-Universidad de Navarra \\ minsua@unav.es
}

RESUMEN / ABSTRACT

Este artículo analiza la presencia de la figura del militar en la obra literaria y periodística del mexicano José Joaquín Fernández de Lizardi (1776-1827). Primeramente, se ofrece una contextualización de la estructura castrense en el México de finales de la Colonia y comienzos de la vida independiente; y su vínculo con la normativización general del estado militar en la España ilustrada. A continuación, el trabajo, que se enmarca en un estudio más amplio de los modelos sociales en la obra lizardiana, revisa la presencia del militar (soldados, oficiales, milicianos) a partir de sus rasgos modélicos y antimodélicos en las novelas, artículos de prensa y otros escritos del autor.

Palabras Clave: México (1810-1827), Fernández de Lizardi, instituciones militares en España y América, figura del militar, modelo social.

This article analyses the presence of the military man in the journalistic and literary work of the Mexican José Joaquín Fernández de Lizardi (1776-1827). Firstly, it offers a contextualization of the military structure in the transition between colonial and independent periods in Mexico; and its link with the general regulation of the army state in the Spain of the Enlightenment. Following, the essay - which is part of a more extensive study of the social models in the work of Lizardi-revises the image of the military man (soldiers, officials, militiamen) taking into account the exemplary and non-exemplary features in the author's novels, journalistic articles and other texts.

KEY WORDS: Mexico (1810-1827), Fernández de Lizardi, military institutions in Spain and Hispanic America, military man image, social model. 
En trabajos anteriores se ha planteado que la prolífica y polémica obra del mexicano José Joaquín Fernández de Lizardi (1776-1827) puede ser leída en su conjunto como una "escuela de ejemplaridad cívica" que propone un esquema de rasgos modélicos para diversas figuras sociales con la finalidad de aportar los fundamentos para la construcción de un estado feliz y ordenado ${ }^{1}$. En esta ocasión me centraré en la configuración de la imagen del militar propuesta por el Pensador Mexicano tanto en sus textos literarios como periodísticos. Antes de entrar propiamente en el análisis del tratamiento de la figura castrense en la obra lizardiana, me referiré a la nueva matriz de rasgos del militar como sujeto social en España y en América -especialmente en Nueva España- en el período ilustrado.

Durante el siglo XVIII se produce en España la normativización del estado militar que se relaciona con un fenómeno más profundo, el de las innovaciones en el mundo de la guerra ${ }^{2}$. Bajo la impronta de la monarquía borbónica comienzan a organizarse ejércitos regulares y permanentes con sus propios mandos profesionales y el militar pasa a completar su función bélica con la de mantención del orden interno del país. Como indica Sánchez-Blanco, surge una institución dentro del complejo social, lo cual genera toda una literatura teórica que aborda las nuevas atribuciones de la profesión militar, el renovado prototipo del hombre de armas, sus cualidades y obligaciones, las virtudes que ha de ostentar y los vicios más punibles en él (110-114). Entre estos rasgos definitorios destacan especialmente dos, que se verán abordados además en la obra lizardiana: la disciplina y la uniformidad (Sánchez-Blanco 114).

Esta redefinición del comportamiento que se espera del militar modélico en la Ilustración española, aplicable también en la América hispana, se materializa en las Ordenanzas de S. M. [Carlos III] para el régimen, disciplina, subordinación y servicios de sus ejércitos de $1768^{3}$, basamento de la reforma militar de la época (Terrón-Ponce 168-169). Tal como señala Pérez de Tudela y Bueso, esta normativa se diferencia de la precedente Ordenanza del Ejército de 1728 en que no está centrada únicamente en la

Ver Insúa, La mujer casada ..., "El modelo del maestro...", "El retrato del periodista...", "La falsa erudición..." y "El ciudadano trabajador...".

2 Una sistematización de este tema puede verse en García Hernán, "La guerra en el siglo XVIII...”.

Ordenanzas de S.M. para el régimen, disciplina, subordinación y servicios de sus ejércitos, Madrid, por don Antonio Marín, Impresor de la Secretaría del Despacho Universal de la Guerra, 1768. 
valoración de la disciplina que tiene como centro al monarca, sino también en la fundamentación moral de los deberes de todas las jerarquías militares, desde los soldados hasta la oficialidad. Con ello se enfatiza el papel del militar en la sociedad con unas responsabilidades éticas determinadas (382). Así, por ejemplo, en el Tratado II de la nueva Ordenanza se conmina a que se entere al soldado desde que sienta plaza de que "el valor, prontitud en la obediencia, y grande exactitud en el servicio, son objetos a que nunca ha de faltar, y el verdadero espíritu de la profesión" (Ordenanzas, Tratado II, Título I, 5, 58-59) o que los oficiales han de valorar como su principal cometido el "cumplir exactamente con las obligaciones de su grado; [...] acreditar mucho amor al servicio, honrada ambición, y constante deseo de ser empleados en las ocasiones de mayor riesgo y fatiga, para dar a conocer su valor, talentos y constancia" (Ordenanzas, Tratado II, Título XVII, 3, 167). De este modo, la actuación militar empieza a regirse ahora por unas normas definidas y el heroísmo pasa a estar al servicio de la colectividad (García Hernán 360, siguiendo a Corvisier 200-201).

Este intento edificante de los distintos estratos del escalafón militar se observa también en otras obras de ámbito castrense con un marcado sesgo moral, como es el caso de la Instrucción militar cristiana de $1788^{4}$. Este catecismo se centra en la máxima de que el militar debe ser ante todo un hombre de bien, amante de la religión, porque solamente así podrá cultivar las virtudes del auténtico héroe que mira hacia la santidad, que actúa pensando en su salvación más que en la gloria terrena. De este modo, se abordan en el texto cuestiones como las prendas que han de adornar al perfecto militar-el amor a la religión, la subordinación al superior, la fortaleza, la disciplina, el celo patriótico... (53)-y también los vicios más reprobables en un hombre de armas -la blasfemia, el excesivo gusto por el juego, la embriaguez, la lujuria, la injusticia, la cólera, la sed de venganza, la ociosidad... (26 y 47)-. Con ello el militar, como cualquier mortal -y de acuerdo con la idea tópica de la vida humana como una milicia contra la malicia-, habría de librar la principal guerra consigo mismo, en lucha permanente con las tentaciones del mundo ${ }^{5}$.

$4 \quad$ Instrucción militar cristiana para el ejército y armada de S.M., Madrid, Pedro Marín, 1788. Corresponde a la reedición de un texto precedente de 1774 titulado Instrucción militar cristiana para uso de caballeros cadetes del Colegio Militar de Segovia que provenía a su vez de la traducción de 1735 de un texto francés de 1729. Ver Gil Muñoz 143.

Como señala Ignacio Arellano en su edición de Los sueños de Quevedo, el motivo de la vida del hombre como guerra tuvo gran presencia en el Siglo de Oro (181, n. 58) y su influencia, como vemos, alcanza también al período ilustrado. 
Por otro lado, un aspecto que se debe destacar en la configuración de estas nuevas pautas de comportamiento del militar durante la Ilustración se refiere no ya a su hacer desde la esfera moral, sino a su actitud frente a los otros grupos de la población, es decir, a su incorporación a las prácticas de la sociabilidad ${ }^{6}$. Con ello el hombre de guerra se convierte también en un actor más en el engranaje social que participa en instituciones civiles, Reales Academias, Sociedades Económicas de Amigos del País y tertulias, que asiste a los cafés... Actuaciones que serán valoradas, pero también en algunas ocasiones criticadas, como veremos en el caso de Lizardi.

El amplio programa de reformas impulsado por Carlos III, cuyo eje central lo constituyen la hacienda y el ejército, se adapta al ámbito americano y a las urgentes necesidades defensivas frente a las incursiones extranjeras. Una de las cuestiones que más preocupaba a la Corona era la de la sustentabilidad económica del estado militar en las colonias. Por ello se desarrolla un plan de acción que contempla la participación de los americanos en las tareas militares y en el costo material de la defensa, a fin de poder asegurar la continuidad del imperio (Suárez 112-113 y Archer 18-19). Esta total reorganización del estado militar indiano se afirma, como señala Marchena Fernández, en la dignificación de esta institución y en el enaltecimiento de la carrera de las armas (92).

Así, a comienzos del siglo XVIII, se reforman en América las guarniciones: las conocidas como "compañías de presidio" se transforman en unidades regulares, desaparece la figura del "soldado de fortuna" y en su lugar nace una oficialidad que trae consigo una serie de requisitos, entre ellos el de la nobleza de sangre, que más adelante será también compatible con la "nobleza de vida" propia de la elite criolla. Del mismo modo que en España, este hecho trae aparejado que la profesión de oficial comience a vincularse al prestigio social y a un estatus de privilegio (Marchena Fernández 93-94 y 167-168). La otra cara social del estado militar la encontramos en los soldados, en la tropa que vive en condiciones miserables, que necesitaba ejercer oficios complementarios alejados de las armas -y en ocasiones negocios que bordeaban la ilegalidad-para poder mantenerse (Marchena Fernández 184-187).

\footnotetext{
Para un análisis de la inserción del militar en la sociedad ilustrada ver Franco Rubio, "Militares ilustrados...".

Para el caso español ver también Andújar Castillo 403-410.
} 
En concreto, en Nueva España la reforma militar se mostró más orgánica y ambiciosa que en el resto de América. Fue llevada a cabo por el lugarteniente general Juan de Villalba y Angulo, quien arribó a Nueva España en 1764 proveniente de Nueva Andalucía, en donde era capitán general (Suárez 239240). El objetivo de su plan de restructuración, aplicado al ejército regular y también a las milicias, era conseguir un estado militar más numeroso y disciplinado. Sin embargo, los resultados no fueron satisfactorios, principalmente porque se dio un gran desajuste en las relaciones entre el poder político y el poder castrense ${ }^{8}$. Otro de los escollos lo constituyó el hecho de que el pueblo llano se mostraba reacio a sumarse a los cuerpos milicianos, lo que llevó a tener que sostener la fuerza bélica con los militares veteranos, del ejército regular. Más allá de todos los factores posibles del fracaso, como señala Archer, el problema central para la plasmación de esta reforma fue la propia Nueva España, por su variada constitución social que conllevaba prejuicios de uno y otro lado (29).

Otro aspecto importante en este contexto de reformas es el de la aplicación en Nueva España del fuero, un conjunto de prerrogativas legales que amparaba a los miembros del estado militar otorgándoles privilegios jurídicos y económicos, las cuales se sustentaban en las ordenanzas militares de 1768. En el caso novohispano, este fuero se aplicaba al ejército regular, pero también se extendió en algunos puntos a las milicias para fomentar el alistamiento (Marchena Fernández 108-109). Estos privilegios, que en teoría eran beneficiosos, en la práctica se convirtieron en una especie de salvoconducto para que muchos de los miembros del estado militar "escaparan de la ley" (McAlister 33) y adoptaran comportamientos alejados del modelo castrense que se estaba procurando construir. Por ello, Francisco Crespo -un subinspector general al que el virrey Gálvez encargó un estudio del estado del ejército en Nueva España- señalaba en su "Dictamen" de 1784 que los privilegios de la milicia eran perjudiciales para su buen gobierno (Cit. en McAlister 69). En un sentido similar, Fernández de Lizardi, cuarenta años después, cuando ya soplan otros vientos políticos y se vela por la construcción ordenada de la república mexicana, señalará en un folleto que el fuero militar no es positivo y que todos los ciudadanos han de ser iguales ante la ley ("Mañas viejas, gobiernos nuevos" (1824), en Obras XIII, 75-76).

8 Sirva como ejemplo de estas relaciones conflictivas la disputa entre el virrey Joaquín de Monserrat, marqués de Cruillas, y Juan de Villalba y Angulo recogida en Archer 25-27. 
Con respecto al paradigma del militar ejemplar en el ámbito mexicano, puede ayudarnos para entrar en materia lo expuesto por el capitán Manuel de la Sotarriba hacia 1798-1799 en una causa por adulterio contra un subteniente del Regimiento de Infantería de Nueva España. En este texto expresa el letrado de la defensa que es imprescindible que el militar actúe siempre conforme a la rectitud moral, y que en ello reside el verdadero heroísmo, pues "los militares virtuosos son los modelos que presenta la historia al referir las acciones grandes y sublimes. En medio de los combates, de las más sangrientas acciones y difíciles conquistas, brillan el honor, la piedad, la sabiduría, la verdad y las otras excelencias que los adornaron"9.

En la obra de Fernández de Lizardi abundan las referencias a cómo debe ser el comportamiento del hombre de armas. Una reflexión muy ilustrativa se halla inserta en El Periquillo Sarniento (1816) y corresponde al capítulo en que el coronel, mentor del protagonista durante su travesía a Manila, entre otras muchas lecciones edificantes, dedica varios parlamentos a la profesión militar $^{10}$. Así, el narrador cuenta que el virtuoso coronel era consultado con frecuencia por los fiscales militares para saber cómo actuar y destaca que junto a él se podía aprender el profundo sentido de esta disciplina. Es decir, que las armas no estaban reñidas con las letras y que un militar también podía ser sabio (El Periquillo 698-699). Aconseja asimismo a su discípulo que, si quiere ser militar, vista "decente sin afeminación", sea "franco sin llaneza", "valiente en la campaña", "jovial y dulce en su trato", "moderado en sus palabras", en suma, un caballero y "hombre de bien en todas sus acciones" (700). Insiste además en que estos atributos deben ser cultivados con especial atención por los oficiales, porque "lo que en un soldado merece pena como dos, en un oficial debe merecerla como cuatro" (700).

Esta misma idea de caballerosidad ejemplar será retomada por Lizardi en Don Catrín de la Fachenda (aprobada por la censura en 1820, publicada post mortem en 1832), cuando el militar Modesto intenta que el pícaro

$9 \quad$ Fragmento extraído del discurso del capitán de Regimiento de Infantería de la Corona, Manuel de la Sotarriba, letrado de la defensa en la causa por adulterio seguida a Manuel Cubillas, subteniente del Regimiento de Infantería de Nueva España (Archivo General de Simancas, Secretaría de Despacho de Guerr., Leg. 6979, exp. 33, 1798/1799). Tomo la cita de Díez Martín 374.

10 Corresponde al capítulo II del tomo IV: “Aquí cuenta Periquillo la fortuna que tuvo en ser asistente del coronel, el carácter de este, su embarque para Manila y otras cosillas pasaderas". En adelante citaré por El Periquillo Sarniento, ed. Ruiz Barrionuevo. 
Catrín y Tremendo, un soldado sinvergüenza, asuman la carrera militar con seriedad. Modesto les explica que el ser militar resulta incompatible con la vida disoluta y que "el oficial que tiene el honor de militar bajo las banderas del rey, debe ser atento, comedido, bien criado, humano, religioso y de una conducta de legítimo caballero" (Vida y hechos 201) ${ }^{11}$. Como se puede apreciar, en los dos casos señalados el Pensador Mexicano está equiparando la figura del militar con el modelo de vida por excelencia de la Ilustración, el del hombre de bien, que sabe ser mesurado en todos los aspectos de su vida y actuar siempre "desde el justo medio" 12 . Cabe señalar que en su novela $L a$ Quijotita y su prima (1818-1819), Lizardi encarna este actuar modélico del cabal hombre de bien en un coronel, don Rodrigo Linarte, padre y maestro de la virtuosa Pudenciana.

Otro de los aspectos abordados por Lizardi para la profesión militar, y que también se relaciona con este modelo ilustrado del hombre de bien, es el de la función social que ha de desempeñar quien la sigue. Tanto el soldado como el oficial han de ser útiles a la comunidad, como debe serlo cualquier trabajador $^{13}$. Por ello señala en sus artículos de prensa que una de las mayores lacras para la tropa y la oficialidad, cuna de todos los vicios, es el ocio mal entendido ${ }^{14}$, coincidiendo con lo expuesto en otros textos formativos de la época como la citada Instrucción del militar cristiano.

Pero el autor mexicano no se queda exclusivamente en la teoría; sugiere ideas prácticas para mejorar el sistema y entrega una serie de pautas para el provecho de distintas figuras sociales: lo hace con los maestros, con las esposas y madres, con los trabajadores ${ }^{15}$ y también con los militares. De este modo, en 1824, en el momento en que la nación mexicana procura consolidar su independencia, ofrece en su periódico Conversaciones del Payo y el Sacristán un "Proyecto sobre milicias cívicas" (tomo I, núms. 4-5, en

11 Cito por la edición de Insúa 2012.

12 Para una síntesis del concepto de hombre de bien en el período ilustrado ver Álvarez Barrientos 101-105, Insúa, La mujer casada 28-32.

13 Por ejemplo en "Decimasexta conversación del Payo y el Sacristán”, Conversaciones del Payo y el Sacristán, tomo I, en Obras V 191; y en "Pescozón de El Pensador al Ciudadano Censor", en Obras X 299.

Así en "Constitución política de una república imaginaria", Conversaciones del Payo y el Sacristán, tomo II, núm. 24, en Obras V 522.

15 Un análisis de estos modelos sociales en la obra lizardiana puede encontrarse en Insúa, La mujer casada ...; "El modelo del maestro...” y "El ciudadano trabajador...”. 
Obras $V, 101-113)$. Ante el peligro de la invasión de la Santa Liga, sugiere por boca del Sacristán una serie de puntos que pueden ayudar a optimizar la defensa. Expone que lo que necesita la tropa mexicana es disciplina; que los soldados pueden ser aguerridos como lo eran los valerosos insurgentes, pero que no basta con ello, pues en la guerra se requieren "reglas fijas y seguras" (núm. 4, en Obras V, 103). El Sacristán considera imperioso que el sistema defensivo cuente con milicias cívicas bien formadas y nutridas que refuercen al ejército regular. Para aumentar el número de alistados propone una sencilla estrategia: que les cambien el uniforme, porque el que estaba en uso era poco atractivo y parecía más atuendo de lacayo que de hombre de armas; y también que se les retribuya económicamente a través de una prest decente, acorde con la patriótica actividad de defensa de la libertad que estaban llevando a cabo (núm. 5, en Obras V, 108-110). Era esencial, por tanto, para que el sistema de milicias funcionara disciplinadamente que hubiese una retribución económica, y eso es lo que Lizardi está subrayando en este proyecto (núm. 5, en Obras $V, 110)^{16}$.

En otro artículo de este mismo periódico, el Payo aconseja que el presidente cree unos cuerpos de milicia activa denominados "batallones de las legiones de honor de la República" y señala las cualidades que deberían tener los aspirantes a formar parte de ellos: "En el soldado, talla, robustez, edad de veinte a treinta años, disposición, valor y conocimiento de la causa que iba a defender. En los cabos y sargentos, además de esto, instrucción en la ordenanza; y en los oficiales y jefes, honor, valor y patriotismo" (Conversaciones del Payo y el Sacristán, tomo II, núm. 5, en Obras V,308). La participación nunca debería ser forzada y ningún vicioso podría ser aceptado.

El tema de la milicia nacional se retoma en la "Constitución política de una república imaginaria”, inserta igualmente en la Conversaciones del Payo y el Sacristán. El Pensador Mexicano considera primordial aumentar el número de hombres preparados y dispuestos a luchar libremente. Para ello habría que despertar en los ciudadanos el espíritu patriótico (tomo II, núm. 24, en Obras $V, 520-521$ ) y nunca contar con soldados que proviniesen de levas, porque estos son los más prontos a desertar. En este punto, Lizardi parece

16 Ver también Conversaciones del Payo y el Sacristán, tomo I, núm. 12, en Obras $V 163$; y "Verdades peladas, reniegue quien renegare, o segunda aparte del impreso titulado: $\mathrm{Si}$ el gobierno se descuida, trabajos hay con la Liga", Folletos (1824-1827), en Obras XIII 742-743. 
hacerse eco de Cadalso - uno de sus autores favoritos- cuando proponía en las Cartas marruecas que el principal estímulo para un héroe es el patriotismo (164). Cabe señalar, por otro lado, que ya antes de exponer estos proyectos de milicias cívicas Lizardi había adelantado en El Periquillo Sarniento la idea de una defensa sostenida por toda la ciudadanía. Recordemos que en el episodio utópico de Saucheofú, el tután insular contaba que en su sociedad no existía la carrera de soldado porque todos los habitantes debían velar por la seguridad de la isla (El Periquillo 754-755).

Otro aspecto que atiende el Pensador en su Constitución es el del ejercicio de la disciplina. Considera que el pilar de las fuerzas armadas, ya sean veteranas o cívicas, es la subordinación, pero la disciplina habrá de ejercerse con moderación y siempre de acuerdo a las ordenanzas, y así, toda la oficialidad, incluidos los grados más altos, habrán de tener en cuenta que "los soldados no son sus esclavos sino sus compañeros de armas" (Conversaciones del Payo y el Sacristán, tomo II, núm. 24, en Obras $V$, 521). Por ello, en los artículos que siguen se señalan multas, a beneficio del cuerpo de inválidos, para aquellos oficiales que maltraten a los soldados de obra o de palabra. En el artículo 107 se ofrece un listado de normas de actuación para un oficial ejemplar: no tutear a los soldados, no proferir delante de ellos términos obscenos, ni actuar escandalosamente, es decir: no embriagarse, no seducir mujeres, ni jugar con los soldados, porque a fin de cuentas el oficial es modelo para la tropa y ha de ser además "flor de los ciudadanos honrados" (Conversaciones del Payo y el Sacristán, tomo II, núm. 24, en Obras V, 521-522).

La ociosidad, como ya se ha señalado, resulta peligrosa y por ello Lizardi se preocupa también de reglamentar los momentos libres para la tropa. En el artículo 111 se esboza un plan de educación de los soldados en el que recomienda introducir el sistema lancasteriano de enseñanza (que consistía en que los alumnos más aventajados enseñaran al resto) para que todos aprendieran a leer, escribir y contar, otorgando premios a los que lo consiguiesen; crear un sistema de instrucción de oficios en los cuarteles como armeros, sastres, barberos o zapateros, etcétera (Conversaciones del Payo y el Sacristán, tomo II, núm. 24, en Obras $V$, 523-524).

En otros pasajes de su producción, el autor ilustrado, con el objetivo siempre presente de criticar con finalidad aleccionadora, se vale de figuras antimodélicas para mostrar los comportamientos errados. En el caso del militar observamos, por ejemplo, una sátira del tipo del soldado bravucón en su obra de teatro Todos contra el payo y el payo contra todos (en Obras II), cuya acción se ubica en el hospital de dementes de San Hipólito, donde han 
sido encerrados varios representantes de la sociedad. El militar, caracterizado como arrogante, matachín y aspaventoso, aparece en escena con un fusil de palo y actúa con exageración. En el acto tercero, el payo visita el manicomio y todos los locos quieren enseñarle algo. El militar, haciendo gala de su marcialidad, quiere que aprenda a marchar como granadero, pero esto resulta imposible porque el payo es patituerto. Todo queda, pues, en una escena que ridiculiza las actitudes exageradas del militar valentón. En "El pleito de las calaveras" denuncia Lizardi a los desertores: aparece allí una calavera de soldado exponiendo que ha sido recogido en la leva y ha desertado ya dos veces; que para él no hay honor de militar que valga, y que solo le importan la plata, la libertad y las hembras (Suplementos al Pensador Mexicano, en Obras III, 328).

En otros artículos se refiere al excesivo interés por la apariencia de los militares coquetos. Así, por ejemplo, en Cajoncitos de la alacena menciona la ridícula costumbre militar de llevar "terribles bigotes y enmarañadas barbas" y se pregunta si eso es ferocidad o más bien mera imitación de una moda extranjera (Cajoncitos de la alacena, 3 , en Obras $I V$, 186). Asimismo, en otro artículo se critica a unos militares elegantones, falsos patriotas que se hacen pasar por republicanos, pero que en realidad fueron quienes antes habían ayudado a sofocar la libertad nacional batiéndose con los insurgentes. Aparecen estos oficialitos con guantes de cabritilla carmesí y luciendo sus sables; son de los que saben decir armas al hombro, ahu y otras "catrinadas", que bailan el vals, pero que jamás han oído el silbido de una bala. Frente a ellos destacan los insurgentes, quienes, aunque se presentan haraposos, son en realidad los verdaderos patriotas ("Preguntas del pensador al Noticioso general", Conversaciones del Payo y el Sacristán, tomo II, núm. 8, en Obras $V, 351)^{17}$.

De este modo, Lizardi se suma a la crítica a la afectación en todos los órdenes sociales que se da durante el período ilustrado y que se ve retratada, para el caso particular del hombre de armas, en El buen militar a la violeta (publicado póstumamente en 1790) de Cadalso. Esta obra se adecua a la

17 La contraposición del militar bonito y el soldado pobre pero valeroso se aprecia también en el folleto de 1821, "Cincuenta preguntas de El Pensador a quien quiera responderlas", en Obras XI 342-343. 
censura de los comportamientos tachados entonces de "marciales"18, haciendo alusión no exactamente a las prácticas de Marte sino al actuar desenfadado y de costumbres relajadas que bordeaba en muchos casos la inmoralidad. En este tratadito satírico un oficial alecciona a sus cadetes acerca del arte militar de la "violetería", como lo hiciera otro maestro cadalsiano con la ciencia universal en Los eruditos a la violeta. La primera máxima para la juventud militar es que todos los principios se sujeten al imperio de la moda (El buen militar 6). A continuación se jalonan los consejos clave para conseguir el éxito en la carrera de las armas: irreligión, libertinaje, locuacidad, conquista amorosa, constante presencia en cafés y mesas de truco, vestido esmerado y amaneramiento, así como el estar dispuesto a desafiar a duelo al menor agravio.

Estos rasgos del militar violeto son encarnados a la perfección por Taravilla, Precioso y Tremendo en la novela lizardiana Don Catrín de la Fachenda. De estos tres personajes, cuya caracterización nominal es evidente, destaca Tremendo, oficial de regimiento y vividor a toda prueba que conmina al cadete Catrín a que pasee, juegue, se enamore y riña, que sea al fin "corriente, franco y marcial" (Vida y hechos 200). En contraposición, nos encontramos con el oficial Modesto que defiende los principios auténticos de la carrera de las armas. Para ello introduce un extenso alegato contra los militares pendencieros y los duelos y se apoya en autoridades como la Escuela de costumbres de Blanchard $^{19}$ o las mismas Ordenanzas militares de 1768 que incluyen la "Pragmática sobre duelos y desafíos". Catrín sigue los consejos del maestro rufián y, como es de esperar, sus enseñanzas lo llevan a ser expulsado del cuerpo, siguiendo su camino por la senda equivocada.

Las referencias que aporta Lizardi acerca de los vicios de estos militares de pacotilla en Don Catrín y otras más puntuales en sus artículos de prensa ${ }^{20} \mathrm{se}$ corresponden con lo que sucedía efectivamente en la época. En este sentido, señala Marchena Fernández que de cada tres oficiales en América uno no mantenía una conducta acorde con el reglamento. En este contexto, los vicios y para su aplicación a la figura del militar ver Sánchez-Blanco 129-130.

19 Obra muy citada por Lizardi en otros pasajes de su producción, especialmente en La Quijotita y su prima.

20 Así por ejemplo, en un artículo de 1826 del Correo Semanario de México se refería a los frecuentes excesos que cometían los jefes militares en estado de embriaguez. Ver "Despotismo hispano militar", Correo Semanario de México, en Obras VI, 54-55. 
que van a la cabeza son el juego, el alcohol, el mal carácter y la desidia (248-250), todos ellos representados en los mencionados textos lizardianos.

\section{CONCLUSIÓN}

En 1820, Lizardi responde a un texto de fray Mariano Soto conocido como Proclama militar en el que el dominico calificaba a los soldados españoles como "ángeles en la tierra". En su folleto, el Pensador Mexicano rebate que los militares son hombres, no ángeles ni iluminados, y que como tales deben actuar rectamente cumpliendo los deberes que tienen como soldados y como ciudadanos ("La palinodia de El Pensador", en Obras X, 376). El padre Soto responderá a este folleto con otro texto en el que tachará a Lizardi de "antimilitar" 21 , el cual a su vez será rebatido por el periodista en uno nuevo en el que increpa al dominico por tratar de malquistarlo con la tropa ("Defensa de El Pensador y epístola al padre Soto", en Obras X, 421). Más allá de la polémica por esta etiqueta de "antimilitar", se puede afirmar que Fernández de Lizardi fue un hombre de paz más que de guerra y que en los momentos culminantes de la historia de México en su paso de colonia a nación independiente, de los que fue testigo y actor, siempre mantuvo -más allá de las veleidades políticas de las que se le acusaron- la premisa de que las armas no debían estar reñidas con el buen juicio. Así también, en 1820 afirmaba que en la batalla los contrincantes de uno y otro bando -en este caso puntual, realistas e insurgentes- tienen los mismos vicios e irrumpen con el mismo ímpetu en el fragor de la lucha. No obstante -recuerda a pie de página-, aquel que pudiese conservar la serenidad de ánimo, la reflexión juiciosa y la quietud de conciencia en medio del caos bélico, ese podría ser llamado héroe ("Aún ha quedado a las zorras el rabo por desollar", en Obras $X, 414)$. En este mismo sentido, y más allá de la simple exaltación patriótica, alababa en 1821 al Ejército Trigarante al valorar a sus componentes sobre todo por su ejemplaridad y por ser "cúmulo de virtudes" ("El Pensador a las valientes divisiones de los señores Bustamante y Quintanar", en Obras XI, 316).

$21 \quad$ Lo hace en "Descubierto el carácter de la pluma impía blasfema y antimilitar del Pensador Mexicano en su papel titulado 'La palinodia en respuesta al padre Soto' y defendida teológicamente la Proclama militar de este autor”, México: Oficina de D. J. M. Benavente, 1820. 
Como se ha podido apreciar en este recorrido por las referencias lizardianas al tema castrense, es en el comportamiento modélico donde se manifiestan para el Pensador el acto heroico y el amor decidido por la patria ${ }^{22}$. Unos llevaban a cabo este cometido desde las filas, y él, con la pluma que fue su arma. En efecto, el planteamiento de la ejemplaridad responde al plan general de Lizardi de ofrecer a sus lectores un conjunto de modelos de vida que aporte a la sociedad mexicana normas de conducta abocadas a organizar el Estado naciente. Fernández de Lizardi, en sintonía con los planteamientos ilustrados europeos, defiende la máxima del orden y el respeto mutuo -es decir, la norma del bien común- y para ello se vale de la presentación de figuras ejemplares y antiejemplares que han de ilustrar con claridad y sin ambages, de modo pedagógico, los comportamientos dignos de emulación y aquellos que se han de evitar para no romper la armonía social. La figura del militar, como agente que ha de velar por ese orden social interno y externo, ocupa un lugar destacado en el mapa social mexicano de aquellos años de cambios políticos tan complejos. El Pensador supo otorgar a los hombres de armas una función señalada en su obra periodística y literaria, a sabiendas de que su rol sería fundamental en la plasmación del México del futuro y que su actuar antimodélico podría ocasionar graves perjuicios a la nación.

\section{BIBLIOGRAFÍA}

Álvarez Barrientos, Joaquín. Ilustración y Neoclasicismo en las letras españolas. Madrid: Síntesis, 2005.

Andújar Castillo, Francisco. Los militares en la España del siglo XVIII. Un estudio social. Granada: Universidad de Granada, 1991.

Archer, Christon I. El ejército en el México borbónico (1760-1810). México: Fondo de Cultura Económica, 1977.

Cadalso, José de. Cartas marruecas. Noches lúgubres. Ed. Rusell P. Sebold. Madrid: Cátedra, 2002.

Cadalso, José de. El buen militar a la violeta. Sevilla: Imprenta Mayor, 1790.

Corvisier, André. Armées et sociétes en Europe de 1494 a 1789. París: P.U.F, 1976.

22 Así lo señala en su folleto "Por la salud de la patria se desprecia una corona", en Obras XII, 337-338. 
Díez Martín, María Teresa. "Representaciones y prácticas de género en la proyección del colectivo social de la oficialidad militar. Una estrategia de la política colonial en el siglo XVIII". Destiempos 14 (2008): 354-396.

Franco Rubio, Gloria. "Militares ilustrados y prácticas de sociabilidad". Revista de Historia Moderna (Anales de la Universidad de Alicante) 22 (2004): 7-86.

Fernández de Lizardi, José Joaquín. El Periquillo Sarniento. Ed. Carmen Ruiz Barrionuevo. Madrid: Cátedra, 1997.

Obras II. Teatro. Ed. Jacobo Chencinsky y pról. Ubaldo Vargas. México: Universidad Nacional Autónoma de México, 1965.

Obras III. Periódicos. El Pensador Mexicano. Ed. María Rosa Palazón y Jacobo Chencinsky. México: Universidad Nacional Autónoma de México, 1968.

Obras IV. Periódicos. Alacena de Frioleras, Cajoncitos de la Alacena, Las Sombras de Heráclito y Demócrito, El Conductor Eléctrico. Ed. María Rosa Palazón. México: Universidad Nacional Autónoma de México, 1970.

Obras V. Periódicos. El Amigo de la Paz y de la Patria, El Payaso de los Periódicos, El Hermano del Perico que cantaba la Victoria, Conversaciones del Payo y el Sacristán. Ed. María Rosa Palazón. México: Universidad Nacional Autónoma de México, 1973.

Obras VI. Periódicos. Correo Semanario de México. Ed. María Rosa Palazón. México: Universidad Nacional Autónoma de México, 1975.

Obras VII. Novelas. La educación de las mujeres o La Quijotita y su prima. Vida $y$ hechos del famoso caballero don Catrín de la Fachenda. Ed. María Rosa Palazón. México: Universidad Nacional Autónoma de México, 1980.

Obras X. Folletos (1811-1820). Ed. María Rosa Palazón e Irma Fernández. México: Universidad Nacional Autónoma de México, 1981.

Obras XI. Folletos (1821-1822). Ed. Irma Fernández. México: Universidad Nacional Autónoma de México, 1991.

Obras XII. Folletos (1822-1824). Ed. Irma Fernández y María Rosa Palazón. México: Universidad Nacional Autónoma de México, 1995.

Obras XIII. Folletos (1824-1827). Ed. María Rosa Palazón e Irma Fernández. México: Universidad Nacional Autónoma de México, 1995.

Noches tristes y dia alegre. Vida y hechos del famoso caballero don Catrín de la Fachenda. Ed. Mariela Insúa. Madrid: UNED, 2012.

García Hernán, David. "La guerra en el siglo XVIII: las innovaciones”, Encuentros Históricos España-Suecia. Los ejércitos y las armadas de España y Suecia en una época de cambios (1750-1870). Coord. Enrique Martínez Ruiz, Magdalena de Pazzis Pi Corrales, Juan Torrejón Chaves. Ciudad Real: Fundación Berndt Wistedt/Universidad de Cádiz/Fundación Municipal de Cultura Ayuntamiento de San Fernando, 2001. 355-376.

Gil Muñoz, Margarita. "Religión y milicia en la segunda mitad del siglo XVIII", Ejército, ciencia y sociedad en la España del Antiguo Régimen, Coord. Emilio Balaguer y Enrique Giménez. Alicante: Instituto de Cultura Juan Gil Albert, 1995. 133-147.

Insúa, Mariela. La mujer casada en la Nueva España de la Ilustración: la obra de José Joaquín Fernández de Lizardi. Gijón: Fundación Foro Jovellanos del Principado de Asturias, 2009. 
"El modelo del maestro en El Periquillo Sarniento de Fernández de Lizardi", Textos sin fronteras. Literatura y Sociedad, 2. Coord. Hala Awaad y Mariela Insúa. Pamplona, Ediciones digitales del GRISO, 2010. 83-102. Disponible en: http://www. unav.es/publicacion/literatura_y_sociedad_IV/Publicacion.

"El retrato del periodista en la obra de José Joaquín Fernández de Lizardi”. Alpha 33 (2011): 159-170.

“La falsa erudición en la Ilustración española y novohispana: Lizardi”. Estudios filológicos 48 (2011): 61-79.

"El ciudadano trabajador en la transición del México colonial al independiente: la obra de José Joaquín Fernández de Lizardi”. Taller de Letras Número especial 1 (2012): 165-177.

Marchena Fernández, Juan. Ejército y milicias en el mundo colonial americano. Madrid: Mapfre, 1992.

McAlister, Lyle N. El fuero militar en la Nueva España (1764-1800). México: Universidad Nacional Autónoma de México, 1982.

Ordenanzas de S.M. para el régimen, disciplina, subordinación y servicios de sus ejércitos. Madrid: por don Antonio Marín, Impresor de la Secretaría del Despacho Universal de la Guerra, 1768. Edición facsimilar: Valladolid: Editorial Lex Nova, 1999.

Pérez de Tudela y Bueso, Juan. De guerra y paz en las Indias. Madrid: Real Academia de la Historia, 1999.

Quevedo, Francisco de. Los sueños. Ed. Ignacio Arellano. Madrid: Cátedra, 1991.

Sánchez-Blanco, Francisco. "Los militares y la sociedad”. La Ilustración goyesca. La cultura en España durante el reinado de Carlos IV (1788-1808). Madrid: CSIC, 2007. 110-138.

Suárez, Santiago Gerardo. Las milicias. Instituciones militares hispanoamericanas. Caracas: Academia Nacional de la Historia, 1984.

Terrón-Ponce, José L. La casaca y la toga. Luces y sombras de la reforma militar durante el reinado de Carlos III. Mahón: IME, 2010. 